\title{
Ovarian development in Wistar rat treated prenatally with single dose diisobutyl phthalate
}

\author{
Ray B ${ }^{1}$, D' Souza AS ${ }^{1}$, Kumar V'1 , Pugazhandhi B' ${ }^{1}$, D’Souza MR ${ }^{2}$, Nayak D ${ }^{1}$, Sushma RK ${ }^{1}$, \\ Shetty $\mathrm{P}^{1}$, Singh $\mathrm{H}^{1}$, Krishna $\mathrm{L}^{1}$, Bhat $\mathrm{KMR}^{1}$, Rao $\mathrm{ACK}^{3}$, Chakraborti $\mathrm{S}^{4}$, Kumar $\mathrm{N}^{5}$, Saxena $\mathrm{A}^{6}$
}

Department of Anatomy, Kasturba Medical College, Manipal, Karnataka, India. biswabina@yahoo.co.in

\begin{abstract}
Phthalates are a class of industrial compounds with an array of toxicological properties used in day to day life. Diisobutyl phthalate on (DIBP) is used as an additive to keep the plastics soft or flexible (plasticizer) in nitrocellulose plastic, nail polish, explosives, lacquer manufacturing etc. Although DIBP exposure in humans is generally low, people in adhesive industries and pharmaceutical industries are exposed to higher levels. The aim of this study was to determine the effect of single dose of DIBP on developing ovary of Wistar rat. One hundred and eight adult pregnant Wistar rats were divided into control and experimental groups. Rats in experimental group were given DIBP on day 10, 12 and 14 of gestation at $0.375,0.75$ and $1.25 \mathrm{ml} / \mathrm{kg}$ body weight dose intraperitoneally in a single dose. Sections of ovaries collected on day 21 of gestation were stained with hematoxylin and eosin and examined and Masson's trichrome histologically. Sections belonging to the control group showed the presence of oocytes in clusters separated by thin fibrous septa. Degeneration oocytes, empty follicles surrounded by follicular cells without gonocytes in the center were observed in ovarian stroma. Blood vessels in the ovarian stroma were prominent and congested. Around a bunch of follicles total architectural disarray was observed although on special staining fibrosis was not evident. As pregnant women are constantly exposed, effect of DIBP on ovary of a developing fetus would denote the long term consequence in future generations (Fig. 5, Ref. 39). Full Text in PDF www.elis.sk.

Key words: ovary, rat, diisobutyl phthalate, ovarian follicle, embryology, gonocytes.
\end{abstract}

Phthalates are a class of widely used industrial compounds known technically as dialkyl or alkyl aryl esters of 1, 2-benzenedicarboxylic acid. The common forms of phthalates are Diethyl hexyl phthalate (DHEP), Diallyl phthalates (DAP), Di-n-propyl phthalates (DPP), Di-n-butyl phthalates (DBP), and Diisobutyl phthalates (DIBP).

Phthalates with a variety of toxicological properties are used in day to day life. These phthalates are nearly omnipresent in modern society and are found in the plastic items, vinyl flooring, wall coverings, lubricants, adhesives, detergents, nail polish, hair spray and car wash (1).

The adverse effects produced by phthalates are changes in morphology, physiology, growth, development or life span of an organism which results in an impairment of functional capacity and ability to compensate for additional stress (2).

${ }^{1}$ Department of Anatomy, Kasturba Medical College, Manipal, Karnataka, India, ${ }^{2}$ Department of Anatomy, Kasturba Medical College International Centre, Manipal, Karnataka, India, ${ }^{3}$ Department of Pathology, Kasturba Medical College International Centre, Manipal, Karnataka, India, ${ }^{4}$ Department of Pathology, Kasturba Medical College, Mangalore, Karnataka, India, ${ }^{5}$ Department of Anatomy, Melaka Manipal Medical College, Manipal, Karnataka, India, and ${ }^{6}$ Department of Anatomy, VCSG Govt. Medical Science \& Research Institute, Srinagar, Uttarakhand, India

Address for correspondence: Biswabina Ray, MD, Dept of Anatomy, Center for Basic Sciences, Kasturba Medical College, Manipal, 576104-Karnataka, India.

Phone: +91.820 .2922327$

\section{Diisobutyl phthalate}

DIBP (phthalic acid ,di isobutyl ester 1,2-benzenedicarboxylic acid ,bis-(2-methyl propyl) ester di-(isobutyl)-1,2-benzene dicarboxylate) is the branched isomer of DBP and an additive used to keep the plastics soft or more flexible (plasticizer) often in combination with other phthalates. DIBP is used in nitrocellulose plastic, nail polish, explosive materials, lacquer manufacturing, consumer products, blood bags, pharmaceuticals and automobile parts. They are ubiquitous in our environment and most people including pregnant women and their fetuses are exposed to multiple phthalates at a time. Saillenfait et al estimated that exposure of pregnant women to DIBP was $0.12 \mu \mathrm{gm} / \mathrm{kg} /$ day with maximum of $2.9 \mu \mathrm{gm} / \mathrm{kg} /$ day (3).

Several studies have shown that DIBP exposure in humans are generally low, near the limit of detection, though a small percentage of people working in adhesive industries and pharmaceutical industries are exposed to higher levels of DIBP.

The dermal absorption of DIBP has been assessed, along with other phthalates by applying on back and urinary and fecal excretion was assessed (4).

In humans, DIBP is metabolized to monoisobutyl phthalate (MIBP) which can be detected in the urine (5). A recent human study showed urinary MIBP concentrations in mothers were inversely related to anogenital index in male offspring. Total and free mono-n-butyl phthalate in human urine samples after medica- 
tion of a di iso butyl phthalate containing capsule was determined by Seckin et al (6).

Singh et al (1972) administared 0.375, 0.75 and $1.25 \mathrm{ml} / \mathrm{kg}$ body weight of DIBP by intraperitoneal route on gestation day 5 , 10,15 to the pregnant Sprague dawley rat. They found fetal mortality, growth retardation and skeletal abnormalities (7).

According to data produced by the Australian Government ,Department Of Health And Ageing, the toxic level of DIBP by Intraperitoneal route (LD5O) is $4.5 \mathrm{mg} / \mathrm{kg}$ body weight of rat or greater than $1600 \mathrm{mgm} / \mathrm{kg}$ body weight of rat (8).

By the gavage route the rat showed toxicities at different quantities of DIBP. At and above $500 \mathrm{mg} / \mathrm{kg}$ bodyweight the mother rat showed transient decrease in body weight. At $750 \mathrm{mg} / \mathrm{kg}$ and $1000 \mathrm{mg} / \mathrm{kg}$ body weight the parent rat showed marked embryo lethality and teratogenicity. At and above $500 \mathrm{mg} / \mathrm{kg}$ body weight, the fetal rat showed decrease in the body weight and male fetuses with undescendent testis were seen at $500 \mathrm{mg} / \mathrm{kg}$ body weight (3).

DIBP administared by gavage is embryo toxic and teratogenic, and affects the developing male reproductive tract. The male fetuses with undescended testes and visceral and skeletal malformations i.e., fused sternebrae occurred at a significantly higher frequency. Two skeletal variations were, retarded ossification of vertebrae, and predominantly, supernumerary ribs (3).

DIBP caused a substantial 30 to 60 fold increased apoptotic cell death effect on murine macrophages from the three other phthalates (DEHP, DBP, BBP which were studied on mouse macrophage cell line (9).

Endocrine disrupting effect of DIBP can induce malformations and impairment of reproductive function in fetal rats and may have similar effects in humans. DIBP, reduced plasma leptin levels in male and female offsprings and fetal plasma insulin levels. In males, DIBP reduced anogenital distance, testosterone production and testicular expression of Insl 3 and genes related to steroidogenesis. PPAR $\alpha$ mRNA levels were reduced by DIBP at gestational day 19 in testis and liver. In females, DIBP increased anogenital distance and increased ovarian aromatase mRNA levels (10).

In an experiment conducted in pregnant Wistar rats, gestation day 20/21 rather than 19 appeared to be the optimal time for investigating changes in anogenital distance together with reductions in testicular testosterone production and testicular testosterone content. Histopathological effects include Leydig cell hyperplasia, Sertoli cell vacuolisation, and central location of gonocytes and presence of multinuclear gonocytes. Immunohistochemical expression of $\mathrm{P} 450$ scc and StAR proteins in Leydig cells was reduced by DIBP (11).

Individual phthalates DIBP, DBP, DEHP, butyl benzyl phthalate (BBP), DEP, with a similar mechanism of action can elicit cumulative, dose additive effects on fetal testosterone production and pregnancy when administared as a mixture. It decreases testicular testosterone production and caused fetal mortality due to pregnancy loss (12).

\section{Development of ovary}

Gonads appear initially as a pair of longitudinal ridges, the genital or gonadal ridges which develop as a thickening of coelo- mic epithelium and condensation of underlying loose mesenchyme along medial aspect of mesonephros $(13,14)$. Extremely early segregation of germ cells has been observed from the epiblast layer when it is only 10-13 cells thick (15). Primordial germ cells (PGC) remain sequestered in the extra embryonic mesenchyme at the caudal end of the embryo until the embryonic endoderm is produced and gastrulation is completed, and then with folding of the embryo underway the PGCs begin their migration to yolk sac (16). These undifferentiated germ cells migrate towards and settle in sexually undifferentiated gonad $(17,18)$. According to Kemper and Peters (1987) in rat on postcoital day 10, PGCs are found in the invaginating visceral yolk sac endoderm and the base of allantois. On postcoital day 11, those cells are mostly found in ventral and lateral gut wall or in mesenchyme between gut and future genital ridges. On 12 postcoital day, most of the PGCs (94\%) get localized in mesenchyme or in future genital ridges. On 13 postcoital day almost all PGCs had reached the well-developed genital ridges.

The somatic cells in gonad are a result of invasion of the cells of coelomic epithelium into the underlying mesenchyme, which form the "first proliferation" and give rise to the primary sex cords (19-22). In females, these primary cords degenerate and a second generation of cords develops from the surface epithelium and form the ovary. The crucial role of mesonephros in gonadal differentiation was originally proposed by various authors. Byskov showed that rete ovarii, which is equivalent to the mesonephric tubules, is crucial to ovarian differentiation (19).

Ovarian development represents a gradual process which is heralded by the development of stromal elements and blood capillaries at the dorsal margin of gonad. Very soon, these are organized to constitute septa of stromal and vascular tissue that extend deeper into the blastema along a dorso-ventral direction, resulting in a ramified system of interconnected ovarian cords. In sections of the ovary in the third and subsequent months, the cords appear as clusters of cells which may or may not contain primitive germ cells.

In early stages of formation, the female gonad consists of coelomic epithelium covering developing gonad and underlying gonadal blastema, mesenchyme and blood vessels. The central region of gonadal blastema contains a mixture of germ and somatic cells (23). Early folliculogenesis depends upon migration of mitotically dividing extra-ovarian rete cells coming from neighboring mesonephros into the intraovarian rete (24). These somatic cells are the precursors of follicular or granulosa cells. Germ cells and pregranulosa cells grouped in cords earlier get separated into individual primordial follicles by stromal cells $(23,25-27)$.

Folliculogenesis is the process by which a single germ cell gets ingested by somatic or follicular cells. A two-way interaction between germ cells and supporting cells forms an important basis for gonadal differentiation, i.e. formation of follicles (28). Actually the time at which follicles form in different species depends on when the oocytes reach the diplotene stage (27). Just after gonadal sex differentiation in fetal mouse ovary most of the germ cells enter meiosis late on the 14 th or 15 th post coital day $(23,29,30)$.

Aim of the study was to determine the effect of single dose of DIBP on developing ovary of Wistar rat. Our working hypothesis is DIBP affects intrauterine ovarian development in rat.Objec- 
tive is to study the effect of DIBP as a teratogen on early ovarian development.

\section{Materials and methods}

108 Female Wistar rats of an average weight of $200 \mathrm{gm}$ and an average age of 120 days were used in this study and they are housed individually in plastic cages in noise-free, air conditioned animal house with temperature maintained at $75^{\circ} \mathrm{F}$ and on a light dark cycle of 12:12 hours. Humidity was maintained with a minimum of $50 \%$. Rats were fed on diet pellets (Hindustan Lever, Bombay, India) and tap water ad libitum and treated with utmost human care. The experiment was carried out with prior approval from the institutional animal ethical committee. The female rats in their pro-oestrous were caged overnight with males of the same stock (Female : Male = $3: 1$ ). Presence of sperms in the vaginal smear on the following morning confirmed start of gestation and the day was numbered as the day 'zero' of pregnancy.

\section{Experimental Groups}

One hundred and eight adult pregnant Wistar rats were used in the present work. They were divided into two main groups. Group I (54 rats) were treated with equal amount of distilled water and serve as control. Group II (54 rats) were given intraperitoneal injection of DIBP on day 10, 12 and 14 of gestation. The animals of treatment group $(n=6)$ were administared DIBP intraperitoneally in a single dose with the help of a sterile tuberculin syringe. Along with this experimental group, a control group was also maintained and administared equal amount of distilled water alone or left uninjected. DIBP was obtained from Durga laboratories, Manglore, India.

The pregnant rats were sacrificed by cervical dislocation on day 20 of pregnancy. Pups were collected through laparotomy. Ovaries were dissected out approaching from anterior abdominal wall. They were fixed in formalin, embedded in paraffin and sectioned at $8 \mu \mathrm{m}$ thickness. Sections were stained with haematoxylin and eosin stain and Masson's trichrome and examined under microscope. The photomicrographs for histological studies were taken with the help of a Photomicroscope.

\section{Results}

The microscopical examination of heamatoxylin and eosin stained sections of the ovary belonging to the control group showed the presence of oocytes in clusters separated by thin fibrous septa. Degeneration of oocytes was observed in all experimental groups (Fig. 1). Pyknotic and irregular nuclei of oocytes indicated that they were in the process of degeneration. This process of degeneration ultimately resulted in death of the central oocytes. Empty follicles surrounded by follicular cells without gonocytes in the center were observed in ovarian stroma (Fig. 2). Blood vessels in the ovarian stroma were prominent and congested as compared to control (Fig. 3). Damaged follicles were noted and all these together gave an appearance of total architectural disarray with elongated cells giving a hint towards increased fibrosis (Fig. 4).
However, fibrosis was not observed amongst damaged follicles as observed on Masson's trichrome stained slides (Fig. 5). Severity of findings was also tabulated.

\section{Discussion}

In the present study, DIBP caused loss of germ cells leading to empty follicles and eventual loss and regression in size of follicles. As a repair mechanism to the insult, prominent and congested vasculature was noted. Also the process of restoration is ongoing; fibrosis is not yet evident replacing the lost follicles as seen in Masson's trichrome stained slides. Widespread architectural disarray resulted from the above mentioned insult.

Lee et al reported, loss of germ cell development increasing with higher doses of DBP, leading to entire loss of spermatozoa from the tubule, a Sertoli-cells only appearance was observed. Giant cell formation was often a feature associated with loss of germ cells (31). DIBP in high dose group caused complete loss of germ cells in testis. Seminiferous tubular hypoplasia was observed in different doses. In few cases lower doses caused total tubular necrosis (3). Borch et al observed DIBP caused central location of gonocytes in seminiferous tubules and multinuclear gonocytes (11).

DBP and DIBP induced changes in gametes can be explained by their DNA mutating capacity. Kleinsasser et al. reported, using an in vitro comet assay, that DNA damage (single-strand breaks) was significantly induced by DIBP $(354 \mu \mathrm{mol} / \mathrm{mL})$ in human oropharyngeal and nasal mucosa (32). In further work, Kleinsasser et al found that DIBP induced strand breaks in DNA, in both blood lymphocytes and normal mucosal cells from the oropharynx or larynx of patients of head and neck cancer (33).

DIBP is potentially dangerous because it has a similar structure to androgenic hormones in the humans. DIBP was negative for estrogenic activity in a yeast two-hybrid assay (34) and showed extremely weak estrogenic activity in recombinant yeast assay (35). DIBP (up to 10-5 M) had no binding affinity for the estrogen receptor $\alpha$ or $\beta$ in vitro (36) but was also found to induce estrogen receptor $\alpha$-mediated estrogenic activity and possess antiandrogenic activity in vitro but showed no activity towards ER $\beta$ in CHO-K1 cells (37).

According to Kemper and Peters, on day 10, germ cells migrate towards gonadal ridge, on day 12 , they are localized either in the mesenchyme between gut and future genital ridges or in the future genital ridges and on day 13 almost all PGC had reached the well-developed genital ridges, therefore, day 14 is the period after germ cells have settled down in ovary (16). Degeneration of gonocytes was observed mostly when they were affected by the insult while in the process of migration and proliferation, rather than after settlement in gonadal ridge when their rate of proliferation reduces. However, the highest dose affected them considerably. Degenerated gonocytes ultimately gave rise to empty follicles. The germ cells were selectively affected as they remain in highly proliferating state at the period of insult. According to Merchant, PGCs do not contain reserve glycogen and lipid inclusions and move by amoeboid movement which require consumption of energy (13). 


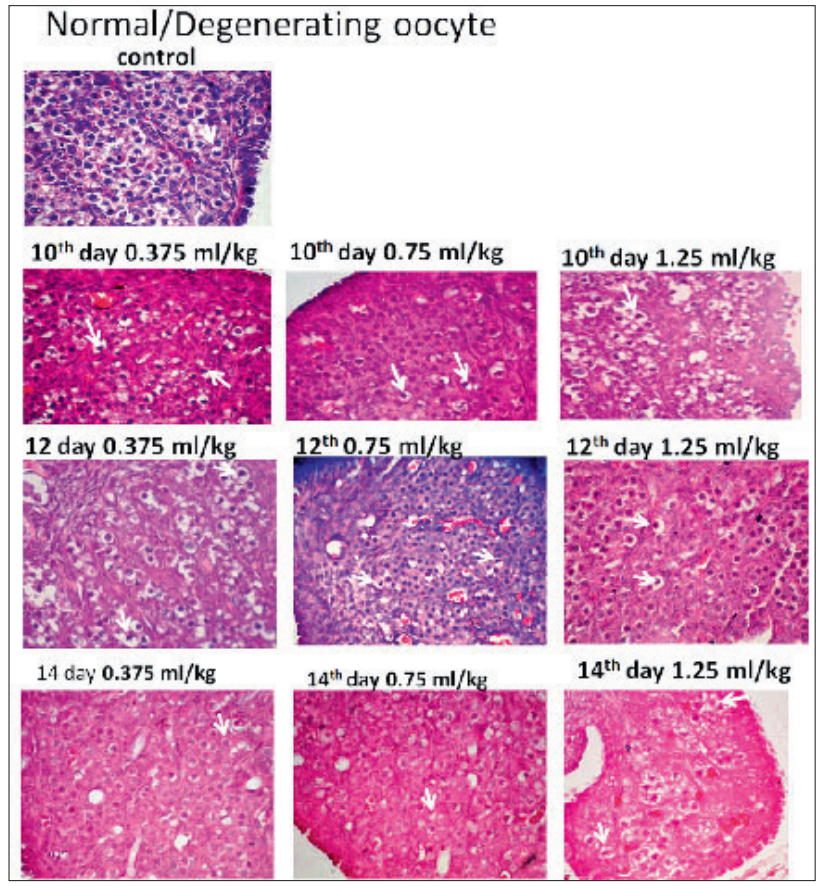

Fig. 1. Photomicrograph showing sections of fetal ovaries with normal oocytes in control and degenerating oocytes in different experimental groups (white arrow). $\mathrm{H} \& \mathrm{E} \times \mathbf{4 0 0}$.

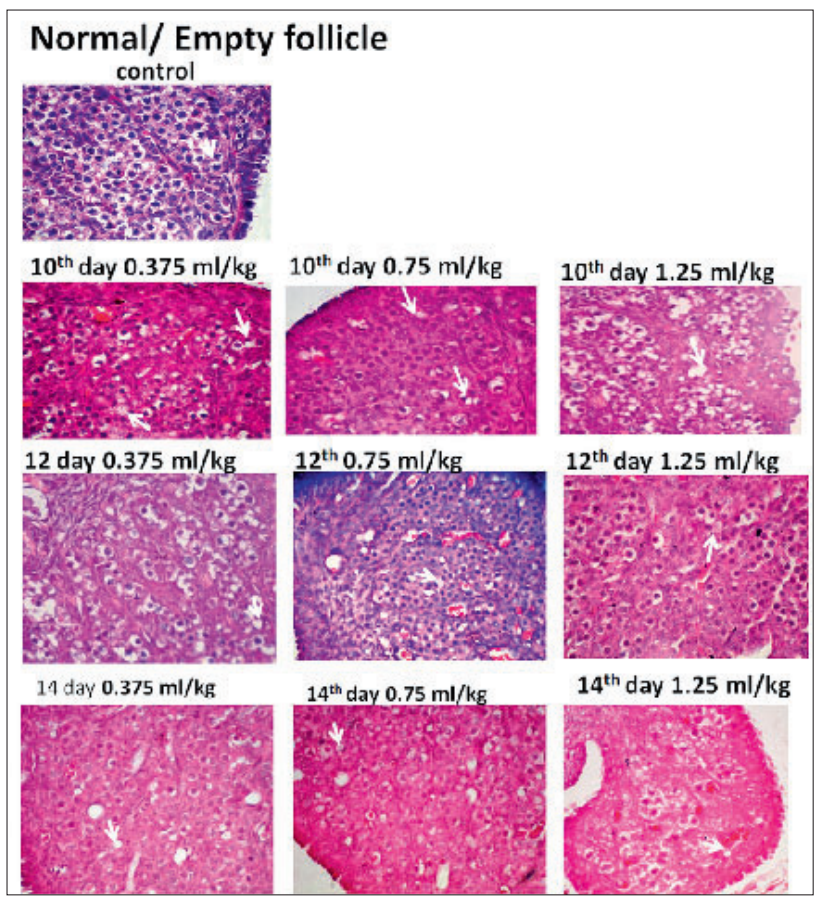

Fig. 2. Photomicrograph showing sections of fetal ovaries with normal oocytes in control and empty follicles surrounded by follicular cells in different experimental groups (white arrow). $\mathrm{H} \& \mathrm{E} \times \mathbf{4 0 0}$.

Gondos observed vacuoles in the cytoplasm immediately adjacent to granulosa cell membranes as well as cytoplasm lying adjacent to the plasma membrane of germ cells show some pinocytic vacuoles associated with phospholipid bodies (38). This arrangement

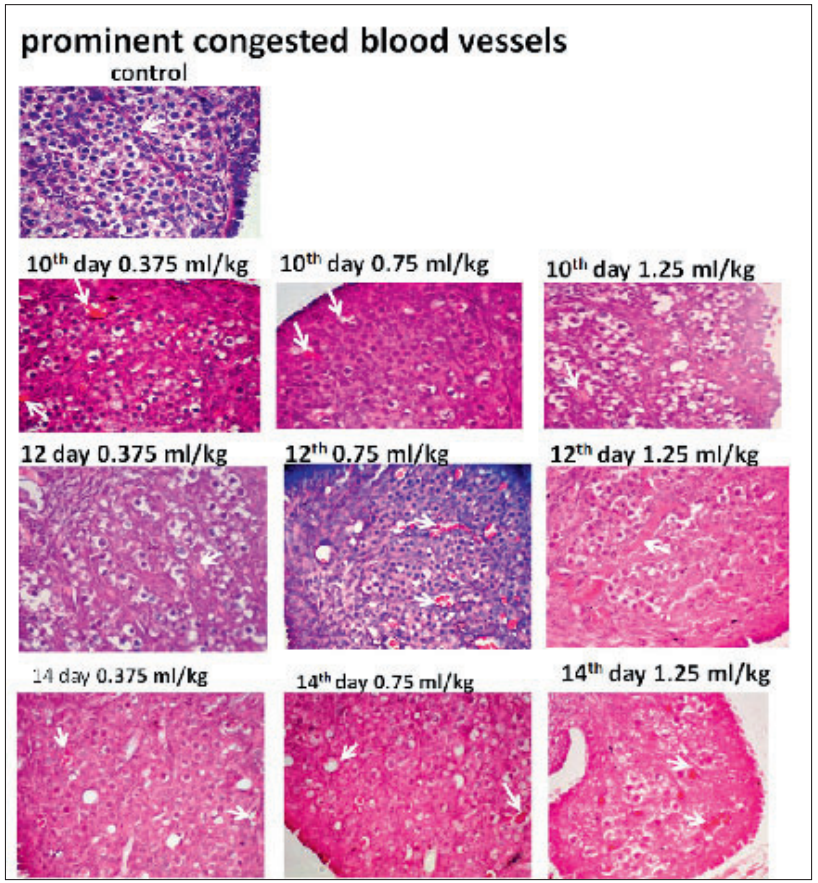

Fig. 3: Photomicrograph showing sections of fetal ovaries with normal vasculature in control and prominent congested vessels in different experimental groups (white arrow). $\mathrm{H} \& \mathrm{E} \times \mathbf{4 0 0}$.

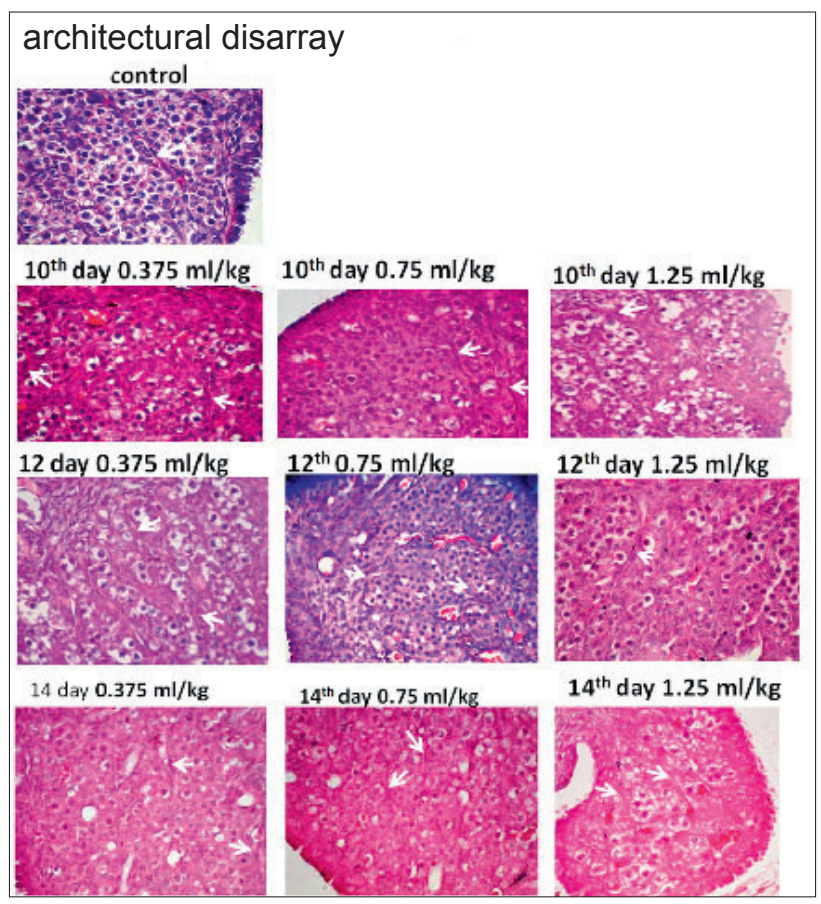

Fig. 4. Photomicrograph showing sections of fetal ovaries with normal fibrous septa in control and architectural disarray in different experimental groups (white arrow). $\mathrm{H} \& \mathrm{E} \times \mathbf{4 0 0}$.

suggests possibility of synthesis of material by granulosa cells, which transfer them directly across the narrow intercellular space for the use of germ cells having limited capacity for synthesis and secretion (39). These intercellular junctions may be involved not 


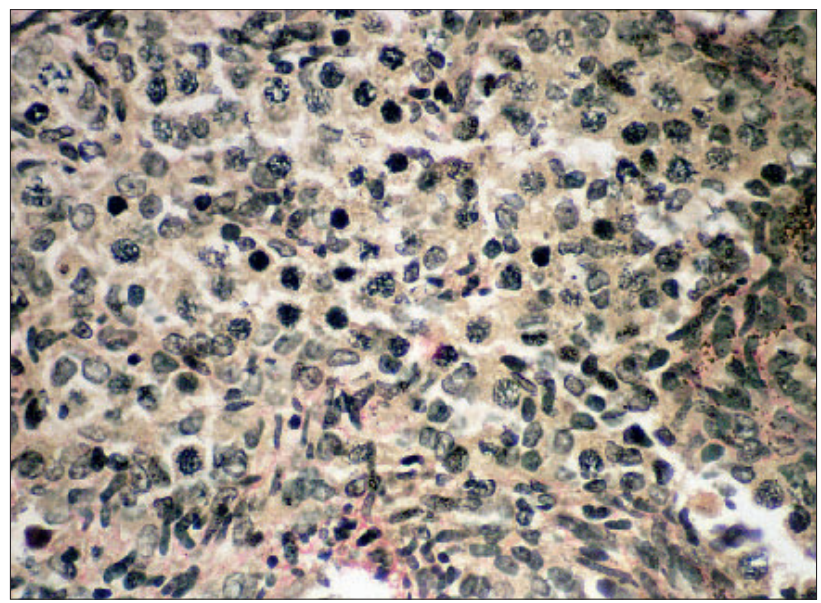

Fig. 5. Photomicrograph showing Masson's trichrome stained sections from experimental group. $\times \mathbf{1 0 0}$.

only in facilitating the migration of germ cells but also in germ cell- somatic cell interaction for providing exogenous substances (gases and nutrients). Therefore, the PGC, which are dependent on surrounding somatic cells for the transfer of nutrient and gases, might have got affected by the injected agent. Prominence and congestion of vasculature and ultimate architectural disarray was prominent with the highest dose of DIBP on 10th and 14th day and the lower 2 doses in 12th day exposure group. Probably 12th day was the most vulnerable period but effects with highest dose were less conspicuous because compensatory mechanisms took over to repair the damage. Although haematoxylline and eosine stained slides gave a hint towards increased fibrosis, it was negated on Masson's trichrome stained slides. Possibly the time gap between the injection and observation was too short for fibrosis to develop.

Our results can be explained based on previous studies where it has been shown that DIBP is known inducer of DNA mutation and stimulates androgenicity and inhibits estrogenicity. On one hand, it has been shown that DIBP causes loss of germ cells, detaches the germ cells from basement membrane which ultimately would result in impending loss in experimental testis $(3,11,31)$.

\section{Conclusion}

Our study indicates that DIBP causes germ cell loss and damage to healthy tissue and total architectural disarray in developing ovary when administared in early stages of gestation. Effect of DIBP on ovary of a developing fetus would denote the long term consequence in future generations.

\section{References}

1. Vikelsoe J. Phthalates released during washing of PVC containing floors and textiles. Danish environmental protection agency reports. 1995

2. Gray LE, Wolf C, Lambright C et al. Toxicol industrial health 1999; 15 (1-2): 94.

3. Saillenfait AM, Sabaté JP, Gallissot F. Developmental toxic effects of diisobutylphthalate, the methyl-branched analogue of di-n-butyl phthalate. Toxicol Lett 2006; 165: 39-46.
4. Elsisi AE, Carter DE, Sipes IG. Dermal absorption of phthalate diesters in rats. Fundam Appl Toxicol 1989; 12: 70-77.

5. Swan S, Main K, Liu F, Stewart S, Kruse R, Calafat A, Mao C, Redmon $\mathbf{J}$, Ternand C, Sullivan S, Teague J \& The-Study-for-Future-Families-Research-Team, Decrease in anogenital distance among male infants with prenatal phthalate exposure. Environ Health Perspect 2005; 113: 1056-1061.

6. Seckin E, Fromme H, Völkel W. Determination of total and free monon-butyl phthalate in human urine samples after medication of a di-n-butyl phthalate containing capsule. Toxicol 2009; 188 (1): 33-37.

7. Singh AR, Lawrence WH, Autian J. Teratogenicity of Phthalate Esters in Rats. Mat Sc Toxicol. 1972.

8. Eastman Kodak Company (1978). Toxicity and health hazard summary: di-isobutyl phthalate. OTS 0206525. DOC \#878214402. Internet resource.

9. Nararala J, A Korpi. Cell death and production of reactive oxygen species by murine macrophages after short term exposure to phthalates. Toxicol Rev 2009; 24: 157-160.

10. Boberg J, Metzdorff S, Wortziger R, Axelstad M. Impact of diisobutyl phthalate and other PPAR agonists on steroidogenesis and plasma insulin and leptin levels in fetal rats. Reprod Physiol 2008; 19, DK-2860.

11. Borch J, Axelstad M, Vinggard AM, Dalgaard M. Antiandrogenic effect of Diisobutyl Phthalate in comparison to Di-n-Butyl phthalate in fetal rat testis Danish Institute for Food and Veterinary Research, Mørkhøj Bygade 2008, 19.

12. Howdeshell KL, Wilson VS, Furr J, Lambright CR, Rider CV, Blystone CR, Hotchkiss A K, Gray LE Jr. A mixture of five phthalate esters inhibits fetal testicular testosterone production in the Sprague dawley rat in a cumulative, dose-additive manner. Reprod Toxicol 2008; 105: 153-165.

13. Merchant $\mathbf{H}$. Rat gonadal and ovarian organogenesis with and without germ cells. An ultrastructural study. Dev Biol 1975; 44: 1-21.

14. Pelliniemi LJ, Frojdman K and Paranko J, The Sertoli Cell. Russell LD and Griswold MD eds. Cache River Press, Clearwater F.L, 1993.

15. Williams PL, Warwick R, Dyson M, Bannistar LH, Eds, Grays anatomy of the human body, 38th edition. London: Churchill Livingstone, 1995.

16. Kemper CH, Peters PWJ. Migration and proliferation of primordial germ cells in the rat. Teratology 987; 36: 117-124.

17. Eddy EM, Fine structural observation on the form and distribution of Nuage in germ cells of the rat. Anat Rec; 1974, 178: 731-758.

18. Wylie CC, Heasman J. Migration, proliferation and potency of primordial germ cells. Sem Dev Biol 1993; 4: 161-170.

19. Byskov AG and Hoyer PE, Embrylogy of mammalian gonads and ducts. In: Knobil E, Neill JD (Eds). The Physiology of Reproduction. New York: Raven Press, 1994, 487-539.

20. Jost A. Development and Function of Reproductive Organs. In: Parvinen M, Huhtaniemi I, Pelliniemi LJ (Eds). Serono Symposia Review No. 14, Rome, Italy, 1988; 2: 1-10.

21. Wartenberg H. Ultrastructure of Human Gametogenesis and Early Embryogenesis. In: Van Blerkom J, Motta J, Motta PM (Eds). Boston: Kluwer Academic Publishers, 1989, 61-84.

22. Hoyer PE, Byskov AG. In Development and Function of Reproductive Organs. In: Byskov AG, Peters H (Eds). Excerpta Medica, Amsterdam, 1981, 216-224.

23. Odor DL, Blandau RJ. Ultrastructural studies on fetal and early postnatal mouse ovaries, Histogenesis and organogenesis. Am J Anat 1969; 124: 163-186. 


\section{$577-582$}

24. Stein LE, Anderson CH. A qualitative and quantitative study of rete ovarii development in the fetal rat: Correlation with the onset of meiosis and follicle cell appearance. Anat Rec 1979; 193: 197-211.

25. Zamboni L, Merchant H. The Development and Maturation of the Ovary and Its Functions. In: Peters H (Ed). Excerpta Med. Found. Amsterdam, 1973, 53-54, 95-100.

26. Makabe S, Nottola SA, Motta PM. Ultrastructure of Human Gametogenesis and Early Embryogenesis. In: Van Blerkom J, Motta J, Motta PM (Eds). Boston: Kluwer Academic Publishers, 1989, 33-60.

27. Guraya SS. Cellular and Molecular Biology of Gonadal Development and Maturation in Mammals. Fundamentals and Biomedical Implications. Narosa Publishing House, 1989.

28. McLaren A. Development of the mammalian gonad: The fate of the supporting cell lineage. Bioessays 1991, 13: 151-156.

29. Mintz B. Continuity of the female germ cell line from embryo to adult. Arch Anat Micr Morph Exp 1959; 48: 155-172.

30. Blandau RJ. Observations on living oogonia and oocytes from human embryonic and fetal ovaries. Am J Obstet Gynecol 1969; 104: 310-319.

31. Lee KY, Shibutani M, Takagi H, Kato N, Takigami S, Uneyama C et al. Diverse developmental toxicity of di-n-butyl phthalate in both sexes of rat offspring after maternal exposure during the period from late gestation through lactation, Toxicology 2004; 203: 221-238.

32. Kleinsasser NH, Kastenbauer ER, Weissacher H, Muenzenrieder RK, Harreus UA. Phthalates demonstrate genotoxicity on human mucosa of the upper aerodigestive tract. Environ Mol Mutagen 2000 a; 35: 9-12.
33. Kleinsasser NH, Wallner BC, Kastenbauer ER, Muenzenrieder, Harreus UA. Comparing the genotoxic sensitivities of human peripheral blood lymphocytes and mucosa cells of the upper aerodigestive tract using Comet assay. Mutat Res 2000 b; 467: 21-30.

34. Nishihara T, Nishikawa J, Kanayama T, Dakeyama F, Saito K, Imagawa M, Takatori S, Kitagawa Y, Hori S, Utsumi H. Oestrogenic activities of 517 chemicals by yeast two-hybrid assay. J Health Sci 2000; 46 (4): 282-298.

35. Harris CA, Henttu P, Parker MG, Sumpter JP. The oestrogenic activity of phthalate esters in vitro. Environ Health Persp 1997; 105: 802-811.

36. Toda C, Okamoto Y, Ueda K, Hashizume K, Itoh K, Kojima N. Unequivocal oestrogen receptor-binding affinity of phthalate esters feaured with ring hydroxylation and proper alkyl chain size. Arch Biochem Biophys 2004; 431: 16-21.

37. Takeuchi S, Iida M, Kobayashi S, Jin K, Matsuda T, Kojima H. Differential effects phthalate ester human oestrogen receptors, Toxicology 2005; 210: 223-233.

38. Gondos B. 239-248. In: Butt WR, Crooke AC, Ryle M (Eds). Gonadotrophins and Ovarian development. Edinburgh: Livingstone, 1970.

39. Wakayama T, Hamada K, Yamamoto M, Suda T, Iseki S. The expression of platelet endothelial cell adhesion molecule-1 in mouse primordial germ cells during their migration and early gonadal formation, Histochem Cell Biol 2003; 119: 355-362.

Received March 16, 2012. Accepted June 26, 2012. 